\title{
Heavy Metals Contamination in Madiwala and Lalbagh Lakes of Bengaluru, Karnataka: Effect of Idol Immersion Activities
}

\author{
Bisweswar Gorain $^{\text {* }}$, V.R. Ramakrishna Parama ${ }^{2}$ and Srijita Paul ${ }^{3}$ \\ ${ }^{1}$ Soil Science, ICAR-Central Soil Salinity Research Institute, RRS (Bharuch), \\ Gujarat - 392012, India \\ ${ }^{2}$ Department of Soil Science, University of Agricultural Sciences, Bangalore, \\ Karnataka - 560065, India \\ ${ }^{3}$ Department of Agronomy, Bidhan Chandra Krishi Viswavidyalaya, \\ West Bengal-741252, India \\ *Corresponding author
}

\section{A B S T R A C T}

Immersion of painted idols and addition of organic wastes in the lake water, as a part of religious activities, is a common religious practice in India. These activities add to the

\section{Keywords}

Idol immersion, Paints, Heavy metals, Water quality,

Conservation, Biological

oxygen demand (BOD),

Chemical oxygen demand (COD)

Article Info

Accepted:

18 September 2018

Available Online:

10 October 2018 contamination of water with alkali, alkaline earth metals and heavy metals and therefore, degrade water quality and limit conservation of good quality water in the lakes. In this pretext, periodic analysis of Madiwala and Lalbagh lake water were carried out to investigate the impact of idol immersion activities on the lake water quality. In Madiwala lake, the maximum concentrations of calcium and magnesium were recorded to be 9.31 and $4.6 \mathrm{ppm}$, respectively after one month of immersion. The maximum concentrations of $\mathrm{Na}$ and $\mathrm{K}$ were 51.3 and $37 \mathrm{ppm}$ respectively, after seven days of immersion in Madiwala lake water. The $\mathrm{pH}$ of the Lalbagh lake water dropped from 8.89 to 8.47 in the post immersion period. The BOD and COD levels also increased from 17.5 and 135.5 to 27.4 and $237.5 \mathrm{mgL}^{-1}$, respectively in Lalbagh lake water which reflects reduction in the dissolved oxygen content of the lake water. The concentrations of different inorganic ions including heavy metals $(\mathrm{Cr}, \mathrm{Cd}, \mathrm{Ni}$ and $\mathrm{Pb})$ were found to increase in the post immersion period. The water of these lakes is used for irrigation as well as for other household purposes in the adjoining areas. Thus, it may pose threat of heavy metal pollution in the near future if the problem is not addressed in due course of time.

\section{Introduction}

Lakes are the dynamic inland aquatic systems sustaining a wide biodiversity. Urban lakes all over the country as well as in the state of Karnataka are subjected to varying degrees of environmental degradation and pollution. The degradation is mainly due to encroachments, eutrophication loads and silt deposition (Anonymous, 2001). The principal causes for the deterioration of water quality in lakes are the discharge of domestic effluents, partially treated or untreated municipal sewage and several toxic pollutants of industrial origin (Jumbe et al., 2008). These anthropogenic activities are also responsible for heavy metals 
contamination. Besides these, immersion of painted idols, reported to contain different heavy metals (Clark et al., 2006; Kumar and Pastore, 2007; Kumar, 2007) was also found to be a potential source of heavy metal pollution in the lake water. Painted idols of Lord Ganesh and Goddess Durga are immersed in the lake water every year in the month of September and October as a part of religious rituals. Likewise, tazias are being immersed in the month of May every year during the Moharum festival. Upon immersion, these paints and chemicals gradually dissolve leading to significant alteration in the water quality (Dhote, et al., 2001).

Addition of Sindur in the water bodies, reported to contain lead and chromium, is very toxic to human beings even at very low concentrations (Bubicz, 1982). The heavy metals added to lake water through the paints are subsequently adsorbed on the surfaces of silt and clay. When the heavy metal laden water and sediments are used for irrigation or as amendment, they are likely to be translocated in the plant parts and enter the human system through food chain. Transfer factors of metals vary in the plant system depending on the soil properties $\mathrm{pH}$, Eh, moisture, microbial diversity, organic matter content etc.) and physiology of the crop grown.

The order of contamination of heavy metals in edible plants follows the order: leafy vegetables > root crops > fruits. It was observed that the use of contaminated lake water for irrigation purpose has not only contaminated the vegetables and cereals but also animal milk (Lokeshwari and Chandrappa, 2006). Lower concentration of essential metals (iron, zinc, copper, etc.) in living organisms causes deficiency disorders whereas their excess leads to toxicity. Regular ingestion of heavy metal contaminated food and water cause biomagnifications in human and animal bodies and may disturb the normal physiological functions. Further, addition of organic matter (leaves, flowers etc.), as a part of these activities, increases BOD and COD levels which in turn affect the aquatic environment adversely (Desai and Tank, 2010). In view of these problems, a study was conducted with the objective of determining the effect of idol immersion activities on the contamination of heavy metals and impact on lake water quality.

\section{Materials and Methods}

\section{Location of the lakes}

Madiwala lake $\left(12^{\circ} 54^{\prime} \mathrm{N}, 77^{\circ} 37^{\prime}\right) \mathrm{E}$ is one of the largest lakes in Bengaluru with an area of $114.3 \mathrm{ha}\left(1.143 \mathrm{~km}^{2}\right)$. It is situated in the BTM Layout and is the destination of many migratory birds. This lake is under the administration of Karnataka State Forest Department which carries out its routine maintenance. Lalbagh lake $\left(12^{\circ} 56^{\prime} \mathrm{N}\right.$, $77^{\circ} 35^{\prime} \mathrm{E}$ ) is a spot of splendid beauty located in the heart of Bengaluru city. It is situated at the southern end of the Lalbagh Botanical Gardens which is well known for the exotic flora. The lake is spread across an area of about 40 acres and has a maximum depth of 3.5 meters. The lake is a prime attraction for nature lovers as well as tourists.

\section{Sampling of lake water}

Water samples were collected from from five randomly selected points of two different lakes of Bengaluru viz. Madiwala and Lalbagh, 30 days before immersion $\left(\mathrm{T}_{1}\right)$ and there after periodically at $1\left(\mathrm{~T}_{2}\right), 7\left(\mathrm{~T}_{3}\right), 14$ $\left(\mathrm{T}_{4}\right), 30\left(\mathrm{~T}_{5}\right)$ and $45\left(\mathrm{~T}_{6}\right)$ days. The water samples were analysed for physico-chemical parameters viz. $\mathrm{pH}, \mathrm{EC}$, alkaline and alkali earth elements viz. $\mathrm{Ca}, \mathrm{Mg}, \mathrm{K}, \mathrm{Na}$ and heavy metals viz. $\mathrm{Cu}, \mathrm{Fe}, \mathrm{Zn}, \mathrm{Mn}, \mathrm{Pb}, \mathrm{Cd}, \mathrm{Cr}$ and $\mathrm{Ni}$. 


\section{Sample preparation}

The analysis of physicochemical properties and estimation of the dissolved metal content were done after filtering the water samples $(500 \mathrm{~mL})$ using Whatman No 41 filter paper (0.45 $\mu \mathrm{m}$ pore size).

The filtrates were preserved with $2 \mathrm{ml}$ nitric acid to prevent the precipitation of metals. The samples were then concentrated on a water bath and subjected to nitric acid digestion prior to the estimation of metals using Atomic Absorption Spectrophotometer (Perkin Elmer Analyst, 700).

The physicochemical and biochemical water quality parameters were analysed using standard procedures (Anonymous, 1975; Anonymous, 1995; Manivasakam, 1987).

\section{Results and Discussion}

Changes in physicochemical properties of lake water due to idol immersion

The EC of the Madiwala lake water increased from 1 to $1.32 \mathrm{dSm}^{-1}$ after 14 days of immersion (Fig. 1). Similar results were in the Tapti river of Surat (Desai and Tank, 2010).

The mean EC observed in the course of the study was $1.17 \mathrm{dSm}^{-1}$ with a standard deviation of $0.12 \mathrm{dSm}^{-1}$.

The EC of the Lalbagh lake water increased from 0.61 to $0.81 \mathrm{dSm}^{-1}$ at $7^{\text {th }}$ day after immersion. The average value of EC observed in the course of the study was $0.72 \mathrm{dSm}^{-1}$.

The $\mathrm{pH}$ of the Lalbagh lake water was found to decrease from 8.89 to 8.47 at $14^{\text {th }}$ day after immersion. Similarly, the $\mathrm{pH}$ of the Madiwala lake water decreased from 7.15 to 6.20 (Fig. 2 ), two weeks after immersion with a standard deviation of 0.43 .
Contamination of lake waters with heavy metals and other inorganic ions

\section{Madiwala lake water}

In Madiwala lake, the higher concentration of Ca was recorded at $30^{\text {th }}$ day post immersion $\left(9.31 \mathrm{meqL}^{-1}\right)$. The average concentrations of $\mathrm{Mg}, \mathrm{K}$ and $\mathrm{Na}$ were also found to follow similar trends in this lake (Table 1).

The concentrations of micronutrients like $\mathrm{Cu}$, $\mathrm{Fe}, \mathrm{Zn}$ and $\mathrm{Mn}$ in Madiwala lake water varied from $0.018-0.039,0.745-1.386,0.108-0.193$ and $0.16-0.45 \mathrm{ppm}$, respectively (Fig. 3, 4, 5 and 6). The Ni content recorded $0.001 \mathrm{ppm}$ before immersion which increased to 0.0056 ppm, 30 days after immersion. However, the mean $\mathrm{Ni}$ concentration of the lake water during the entire course of the study was $0.0025 \mathrm{ppm}$ with a standard deviation of 0.002 ppm (Fig.10). The average concentrations of $\mathrm{Cr}, \mathrm{Cd}$ and $\mathrm{Pb}$ in the lake water were 0.0012 , 0.0020 and 0.0029 ppm, respectively (Fig.7, 8 and 9).

\section{Lalbagh lake water}

The concentration of $\mathrm{Ca}$ recorded was higher at 30 days after immersion $\left(7.1 \mathrm{meqL}^{-1}\right)$ which was nearly two-fold greater than before immersion (3.5 meqL $\left.\mathrm{L}^{-1}\right)$. The average concentration of $\mathrm{Mg}$ also followed similar trends (Table 2).

The mean values of metals such as $\mathrm{Cu}, \mathrm{Fe} \mathrm{Zn}$ and $\mathrm{Mn}$ recorded in Lalbagh lake water were $0.05033,1.348,0.1585$ and $2.25 \mathrm{ppm}$ with corresponding standard deviations of 0.0287 , $0.25178,0.04349$ and $0.91 \mathrm{ppm}$, respectively (Fig. 3, 4, 5 and 6).

The $\mathrm{Pb}$ content recorded before immersion was $0.003 \mathrm{ppm}$ which increased to $0.017 \mathrm{ppm}$, fourteen days after immersion. However, the mean concentration of $\mathrm{Pb}$ in the lake water 
during the entire course of the study was found to be $0.01067 \mathrm{ppm}$ with a standard deviation of $0.00468 \mathrm{ppm}$ (Fig. 9). The average concentration of $\mathrm{Cr}, \mathrm{Cd}$ and $\mathrm{Ni}$ and in the lake was $0.00932,0.00118$ and 0.00503 $\mathrm{ppm}$, respectively. The concentration of $\mathrm{Cr}$,
$\mathrm{Cd}$ and $\mathrm{Pb}$ and $\mathrm{Ni}$ in Bellandur lake ranged from 0.002-0.0157, 0.0002-0.0023, 0.003 0.017 and $0.002-0.0081 \mathrm{ppm}$, respectively (Fig. 7, 8, 9 and 10). The results were in conformity with Das et al., (2012) and Malik et al., (2012).

Table.1 Changes in the alkali and alkaline earth metals concentrations with period of sampling in Madiwala lake of Bengaluru

\begin{tabular}{|c|c|c|c|c|}
\hline $\begin{array}{c}\text { Period of } \\
\text { sampling }\end{array}$ & Calcium & \multicolumn{1}{|c|}{$\begin{array}{c}\text { Magnesium } \\
\left(\text { meq L }^{-1}\right)\end{array}$} & \multicolumn{2}{|c|}{$(\mathrm{ppm})$} \\
\hline $\mathbf{T}_{\mathbf{1}}$ & 1.6 & 0.8 & 28.6 & 39.10 \\
\hline $\mathbf{T}_{\mathbf{2}}$ & 2.5 & 1.4 & 34.3 & 48.60 \\
\hline $\mathbf{T}_{\mathbf{3}}$ & 8.36 & 4.2 & 37 & 51.30 \\
\hline $\mathbf{T}_{\mathbf{4}}$ & 5.33 & 2.9 & 35.5 & 38.00 \\
\hline $\mathbf{T}_{\mathbf{5}}$ & 9.31 & 4.6 & 27 & 42.45 \\
\hline $\mathbf{T}_{\mathbf{6}}$ & 7.33 & 3.1 & 18.4 & 43.35 \\
\hline Mean & 5.73 & 2.83 & 30.13 & 43.71 \\
\hline $\begin{array}{c}\text { Standard } \\
\text { deviation }\end{array}$ & 3.16 & 1.5 & 6.97 & 5.26 \\
\hline
\end{tabular}

$\mathrm{T}_{1}$ : sampling before 30 days, $\mathrm{T}_{2}, \mathrm{~T}_{3}, \mathrm{~T}_{4}, \mathrm{~T}_{5}$ and $\mathrm{T}_{6}$ : sampling $1,7,14,30$ and 45 days after idol immersion activities

Table.2 Changes in the alkali and alkaline earth metals concentrations with period of sampling in Lalbagh lake of Bengaluru

\begin{tabular}{|c|c|c|c|c|}
\hline $\begin{array}{c}\text { Period of } \\
\text { sampling }\end{array}$ & Calcium & \multicolumn{2}{|c|}{ Magnesium } & \multicolumn{2}{|c|}{ Potassium } & Sodium \\
\hline $\mathbf{T}_{\mathbf{1}}$ & \multicolumn{2}{|c|}{$(\mathrm{ppm})$} \\
\hline $\mathbf{T}_{\mathbf{2}}$ & 3.5 & 0.9 & 24.5 & 33.4 \\
\hline $\mathbf{T}_{\mathbf{3}}$ & 4.1 & 1.6 & 26.2 & 35.6 \\
\hline $\mathbf{T}_{\mathbf{4}}$ & 5.5 & 2.7 & 27.8 & 39.2 \\
\hline $\mathbf{T}_{\mathbf{5}}$ & 7.9 & 1.6 & 25.5 & 37.66 \\
\hline $\mathbf{T}_{\mathbf{6}}$ & 4.1 & 3.08 & 23.6 & 34.9 \\
\hline Mean & 4.71 & 1.89 & 22.96 & 35.2 \\
\hline $\begin{array}{c}\text { Standard } \\
\text { deviation }\end{array}$ & 1.34 & 1.96 & 25.09 & 35.99 \\
\hline
\end{tabular}

$\mathrm{T}_{1}$ : sampling before 30 days, $\mathrm{T}_{2}, \mathrm{~T}_{3}, \mathrm{~T}_{4}, \mathrm{~T}_{5}$ and $\mathrm{T}_{6}$ : sampling $1,7,14,30$ and 45 days after idol immersion activities 
Fig.1 Changes in EC $\left(\mathrm{dS} \mathrm{m}^{-1}\right)$ due to idol immersion activities

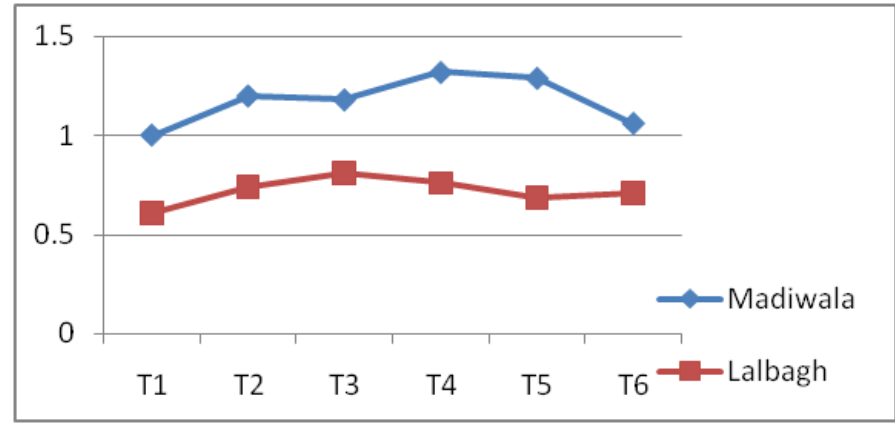

Fig.2 Changes in $\mathrm{pH}$ due to idol immersion activities

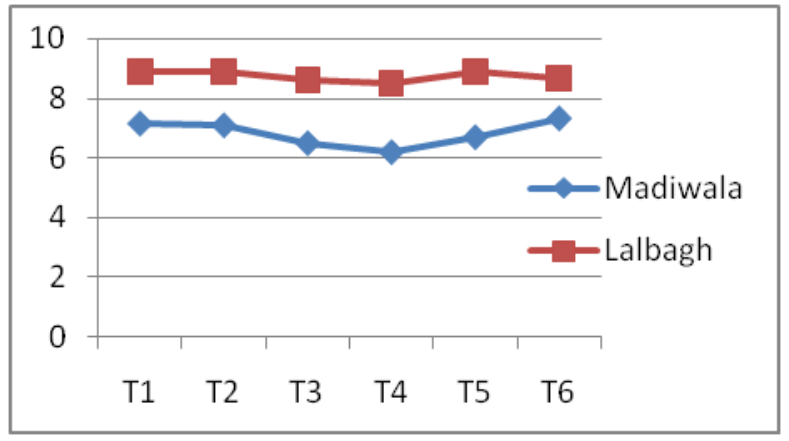

Fig.3 Changes in copper concentration (ppm) due to idol immersion activities

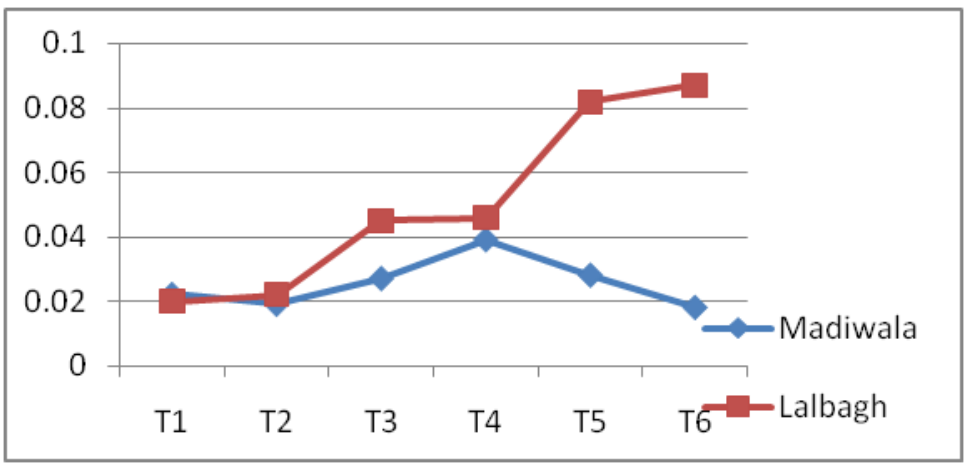

Fig.4 Changes in iron concentration (ppm) due to idol immersion activities

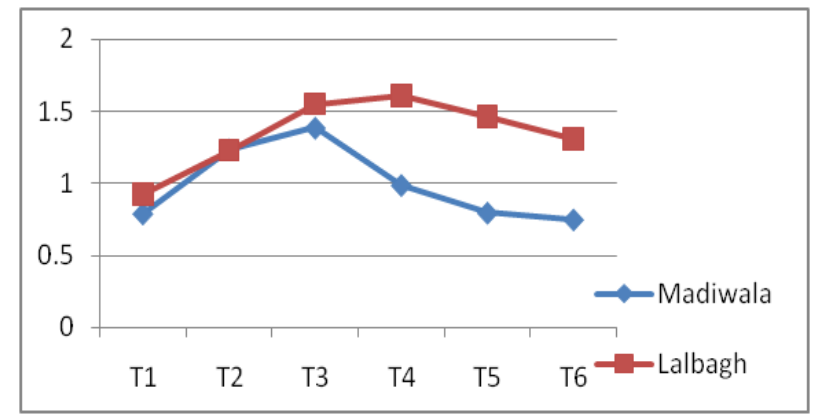


Fig.5 Changes in zinc concentration (ppm) due to idol immersion activities

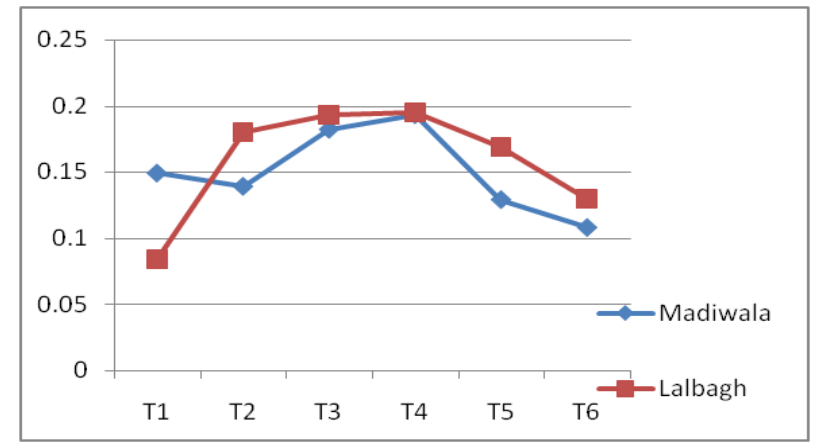

Fig.6 Changes in manganese concentration (ppm) due to idol immersion

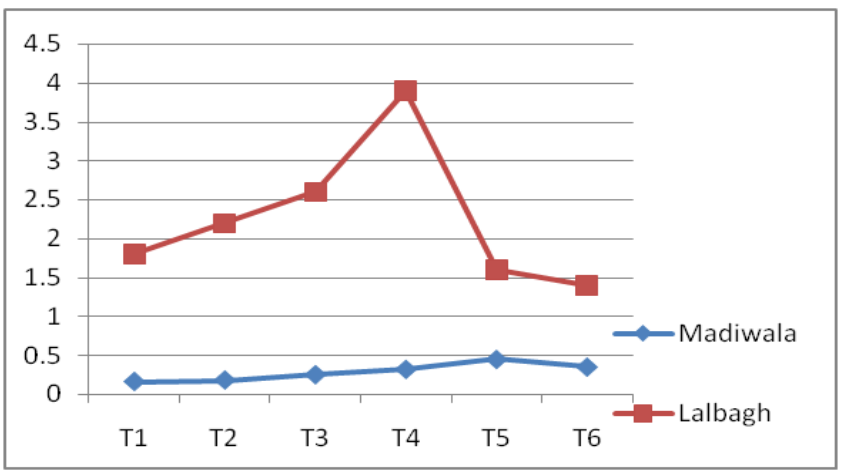

Fig.7 Changes in chromium concentration (ppm) due to idol immersion

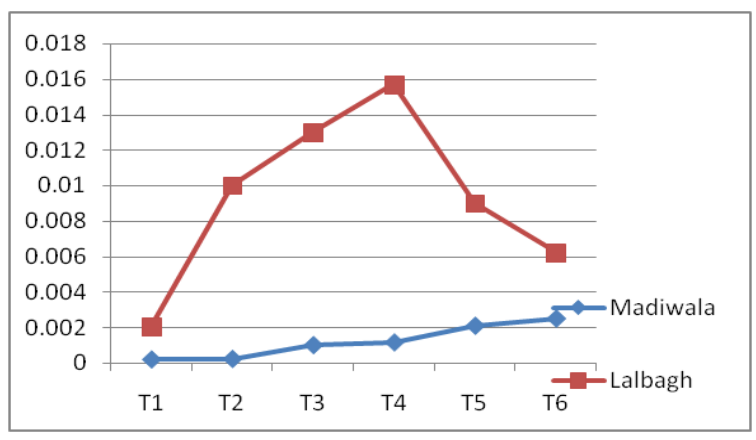

Fig.8 Changes in cadmium concentration (ppm) due to idol immersion

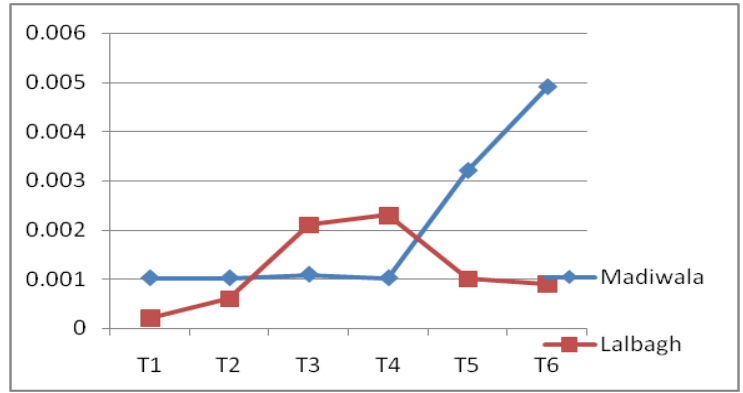


Fig.9 Changes in lead concentration (ppm) due to idol immersion

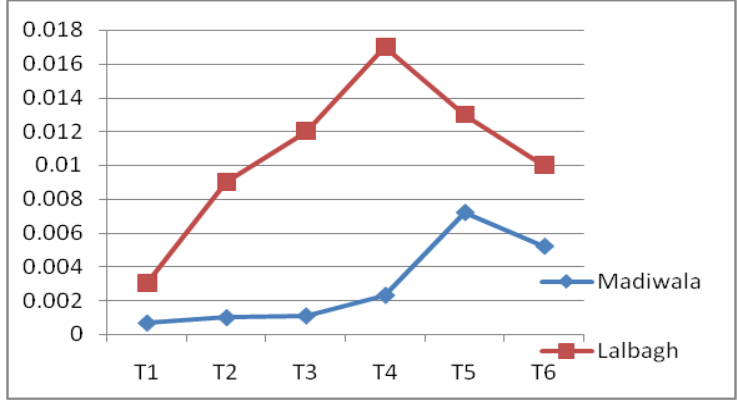

Fig.10 Changes in nickel concentration (ppm) due to idol immersion

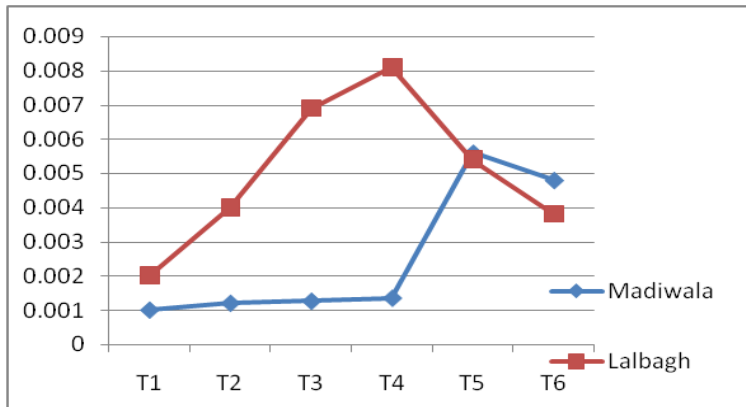

Fig.11 Changes in BOD $\left(\mathrm{mgL}^{-1}\right)$ in lake water due to idol immersion

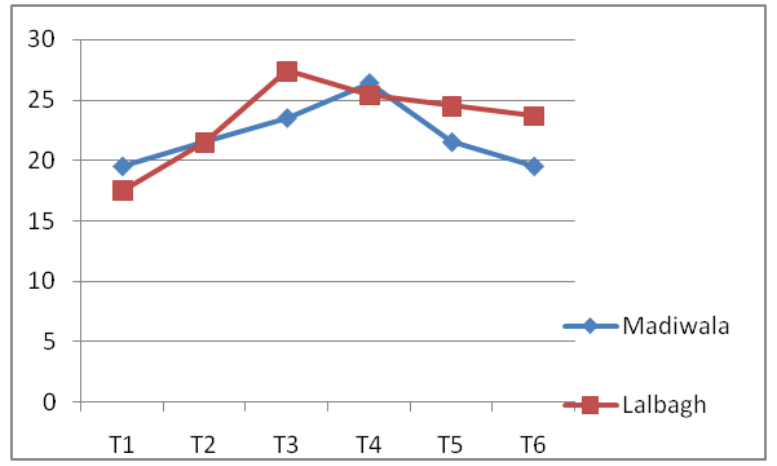

Fig.12 Changes in COD $\left(\mathrm{mgL}^{-1}\right)$ in lake water due to idol immersion

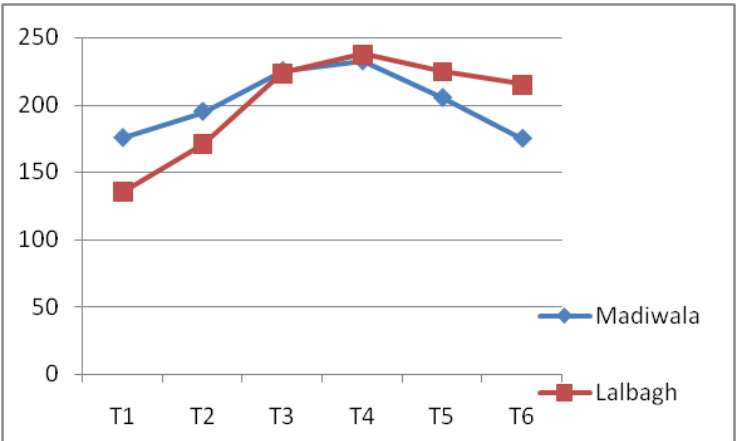


Fluctuation in biochemical properties of lake waters due to idol immersion activities

The BOD of Madiwala Lake, in the preimmersion period was $19.5 \mathrm{mgL}^{-1}$ which increased to $26.4 \mathrm{mgL}^{-1}$ one month after immersion (Fig. 11). However, with time the BOD again decreased to $19.5 \mathrm{mgL}^{-1}$.

The COD of Madiwala lake showed a steep increase from $175.5 \mathrm{mgL}^{-1}$ in the preimmersion period to $232.7 \mathrm{mgL}^{-1}$ at the post immersion period (Fig. 12).

\section{Changes in physicochemical properties of} lake water due to idol immersion

The reduction in EC of the Madiwala lake water (Fig. 1) was might be due to the addition of different salts during the immersion activities. Similar results were in the Tapti river of Surat (Desai and Tank, 2010). The difference in the mean EC of the lake waters is a function of the degree of addition of salts through sewage, sludge, domestic effluents and monsoonal runoff from adjoining agricultural fields along with the extent of idol immersion (Ujjania et al., 2011, Mehta, 2013).

The decrease in $\mathrm{pH}$ may be attributed to the decomposition of organic materials added during the immersion of idols as well as from the other sources. The mechanism can be described by the following equations:

$\mathrm{R}-\mathrm{COOH} \rightarrow \mathrm{R}^{-\mathrm{COO}^{-}}+\mathrm{H}^{+}$(Eq. 1)

$\mathrm{R}-\mathrm{OH} \rightarrow \mathrm{R}^{-} \mathrm{O}^{-}+\mathrm{H}^{+}$(Eq. 2) [R- aliphatic or aromatic moiety]

\section{Contamination of lake waters with heavy} metals and other inorganic ions

The different heavy metals gradually increased with the period of immersion might be due to their different solubility rates as well as seasonal variations. The results were in uniformity with Kaur (2012) in both marine and freshwater systems. The increase in these alkaline earth metals in the long run may increase the hardness of water thereby deteriorating the water quality.

Fluctuation in biochemical properties of lake waters due to idol immersion activities

The fluctuation in BOD of the lake water might be attributed to the dilution of biodegradable organic matter in the large volume of lake water. Similar trend was also observed in Lalbagh lake. The immersion of painted idols was accompanied with the addition of leaves, flowers and other organic materials used in the rituals in the lake waters. These materials upon decomposition increase the BOD and COD levels creating hypoxic conditions in the system.

Madiwala and Lalbagh lakes of Bengaluru have been instrumental in meeting the water demand of the adjoining areas in the lean season. Contamination of these water bodies through industrial and domestic effluents as well as religious activities like idol immersion is creating an uncongenial aquatic environment. This is responsible for the deterioration water quality and also making it unfit for human consumption as well as for agricultural purpose. The increase in BOD and COD levels in the lake water during the course of study reflect significant addition of biodegradable organic matter due to the idol immersion activities. The concentrations of $\mathrm{Ni}, \mathrm{Cr}, \mathrm{Cd}$ and $\mathrm{Pb}$ in the lake water increased in the post immersion period. Since, heavy metals contamination even at very low concentration is detrimental to animal systems, public awareness regarding this problem should be generated. Some of the novel approaches that can be followed to combat this problem are the use of nonpainted clay idols, use of organic dyes instead 
of synthetic paints and utilizing organic wastes like flowers and leaves for compost preparation. In this way, lake water quality may be restored without hurting the sentiments of the religious communities.

\section{Acknowledgement}

The authors are thankful to University of Agricultural Sciences (Bengaluru) for providing the infrastructure and laboratory for conducting the experiment. The first author is thankful to Indian Council of Agricultural Research, New Delhi for the financial support in conducting the experiment.

\section{References}

Anonymous. 1975. Standard Methodsfor Examinations of Water and Waste Water. American Public Health Association, Washington, D. C., $14^{\text {th }}$ Edn, pp. 1-624.

Anonymous. 1995. Standard Methods for Examinations of Water and Waste Water. American Public Health Association, Washington, D.C., $19^{\text {th }}$ Edition. Pp. 1-541.

Anonymous. 2001. Karnataka State Pollution Control Board -Monitoring and Analysis of Tanks and Lakes of Bangalore; Research and Development Wing Publication.

Bubicz, M. 1982. Heavy metal in the aquatic environment of some water bodies of the Lublin basin. Aquatic Hydrobiology 24: 125-138.

Clark, C.S., Rampal, K.G., Thuppil, V., Chen, C.K., Clark, R. and Roda, S. 2006. The lead content of currently available new residential paint in several Asian countries. Environmental Research 102: 9-12.

Das, K.K., Panigrahi, T. and Panda, R.B. 2012. Idol immersion activities cause heavy metal contamination in river
Budhabalanga, Balasore, Odisha, India. International Journal of Modern Environmental Research. 2(6):45404542.

Desai, J. and Tank, S.K. 2010. Deterioration of water quality due to immersion of Ganesh idols in the river Tapti at Surat (India). Journal of Environmental Research and Development. 4(4): 9991007.

Dhote, S., Varghese, B. and Mishrs, S.M. 2001. Impact of idol immersion on water quality of Twin Lakes of Bhopal. Indian Journal of Environmental Protection. 21: 998-1005.

Jumbe, A.S., Nandini, N., Tandon, S. 2008. Bangalore Lakes - Issues and perspectives on pollution, restoration and management. The $12^{\text {th }}$ World Lake Conference. Pp. 1699-1706.

Kaur, R. 2012. Effect of idol immersion on marine and fresh water-bodies. Advances in Applied Science Research 3(4): 1905-1909.

Kumar, A. 2007. Brush with Toxics, An investigation on Lead in Household Paints in India. Toxics Link publication, New Delhi. pp. 1-36.

Kumar, A. and Pastore, P. 2007. Lead and cadmium in soft plastic toys. Current Science 93(6): 818-822.

Lokeshwari, H. and Chandrappa, G.T. 2006. Impact of heavy metal contamination of Bellandur lake on soil and cultivated vegetation. Current Science 91(5): 622627.

Malik, G.M., Raval, V.H., Zadafiya, S.K. and Patel, A.V. 2012, Idol immersion and Physico-Chemical properties of South Gujarat Rivers, India. Research Journal of Chemical Sciences 2(3): 21-25.

Manivasakam, N. 1987. Physico-chemical examination of water, sewage and industrial effluent. Pragathi prakashan publication, Meerut, India. pp 1-268. 
Mehta, P. 2013. Alteration in water quality parameters and consequential impacts due to festival waste in Jodhpur. International Journal of Science and Technology 17(1): 1166-1176.
Ujjania, N.C. and Multani, A.A. 2011. Impact of Ganesh idol immersion activities on the water quality of Tapi River, Surat (Gujarat) India. Research Journal of Biology 1(1): 11-15.

\section{How to cite this article:}

Bisweswar Gorain, V.R. Ramakrishna Parama and Srijita Paul. 2018. Heavy Metals Contamination in Madiwala and Lalbagh Lakes of Bengaluru, Karnataka: Effect of Idol Immersion Activities. Int.J.Curr.Microbiol.App.Sci. 7(10): 2254-2263.

doi: https://doi.org/10.20546/ijcmas.2018.710.260 